\title{
New Equation for Estimating Outdoor Thermal Comfort in Humid-Tropical Environment.
}

\author{
S. Sangkertadi ${ }^{1}$ and R.Syafriny ${ }^{1}$
}

\begin{abstract}
This paper presents the results of research focusing on thermal comfort at outdoor spaces in humid tropical climate. The study was conducted in the city of Manado, Indonesia in the years 2011 and 2012, by way of field-experimentation and measurements of microclimate. From the results of measurements and questionnaires, it was carried out development of regression equations. Through statistical analysis it has been generated three thermal comfort equations for outdoor, which each for normal walking, brisk walking, and sitting with doing a moderate activity. Equations are functions of $\mathrm{Ta}$ (air temperature), $\operatorname{Tg}$ (globe temperature), $\mathrm{v}$ (wind velocity), $\mathrm{RH}$ (Relative humidity) and Adu(body surface area). The output of the equations is scale of thermal comfort level referring to PMV (Predicted Mean Vote), where 0 is comfortable or neutral, +3 is very hot, -2 is cold, .etc. The equations are uniquely for the people wearing tropical clothing type (about 0.5 to 0.7 clo). The validation of the equations was done through comparison with other equations that originated from the studies of non-tropical humid climates. Simulations using the equations were also be done in order to know effect of micro climate on outdoor thermal comfort.
\end{abstract}

Keywords: thermal comfort, tropical-humid, micro-climate, Manado

\section{Introduction}

\subsection{General Background}

The success of architecture and urban design of the cities are determined partly by the creation of thermal comfort that perceived by the users both indoor and outdoor.

However, climatic architecture of outdoor space should also be developed towards the need of thermal comfort at outdoor area. The green cities environment gives examples how outdoor space must be comfortable for people's activities. When designing urban open space facilities, the priority is to design it to be thermally comfortable for the user's satisfaction. It is also underlined by Nasir (2012) that in designing sustainable green space, addressing outdoor thermal comfort and heat stress have become more prevalent focus.

The need of thermal comfort at outdoor is discussed, since an increase of air temperature and humidity in urban areas. The increase of world surface temperature is actually of the impact of global warming due to human activities as effect of urbanization. Many sources show information that nowadays more than $50 \%$ of the world population is living in urban areas. That is why the focus of greenery cities is more attractive in the recent times. Concerning thermal comfort, Fanger (1970) defines the term of thermal comfort as a condition or feeling of satisfaction of the human responding his thermal environment.

\footnotetext{
Departement of Architecture, Faculty of Engineering, Sam Ratulangi University, Indonesia.
} 
Recently, the principal objective of thermal comfort criteria is mostly for standardization of buildings types and its equipments in order to achieve energy efficiency and indoor environmental friendly. However, from the view point of thermal perception, the problem occurred at outdoor space may be different from the indoor situation and may lead to the different concept of thermal comfort for outdoor spaces. The mean radiant temperature of inner surfaces in such indoor spaces is same or almost same as its indoor air temperature due to the closed characteristic of rooms and that well protected from outdoor thermal environment. But at outdoor, especially in tropical regions, average of radiant temperatures is significantly more influenced by direct solar radiation and surfaces temperature (material of streets, pedestrians, buildings envelop, and other surfaces of urban furniture), and may reach a value that much higher than the outdoor air temperature. This paragraph may leads us to put hypothesis that the mean radiant temperature contribute as the most sensitive micro climate component on outdoor comfort of human activities in humid tropical region.

\subsection{The City of Manado and its climate}

Manado is one of the cities that geographically positioned at warm and humid climate region, in Indonesia. The climate is characterized by relatively high air temperature, much sun-light and high humidity. Manado is the coastal city located in 1,5 N and $125 \mathrm{E}$, with habitat of about 410 thousands people in 2012. The population density is about 2650 people $/ \mathrm{km}^{2}$. The average diurnal air temperature is varied between about $20^{\circ} \mathrm{C}$ to $32^{\circ} \mathrm{C}$. Relative air humidity, in average is about $70 \%$ to $90 \%$. Daily solar radiation may reach more than $4000 \mathrm{Wh} / \mathrm{m}^{2}$ (Fig.2 \& 3). Manado is a waterfront city that consisted $20 \mathrm{~km}$ long of coastal lines, having sloping landscape natural scenery and plenty of small rivers flow into the sea. Manado as the capital of province of Sulawesi Utara (North Sulawesi, Indonesia), has great opportunity to develop outdoor space as public places at some strategic areas for providing the need of outdoor activities. As an enjoyable place in the city, open space design should begin with an understanding of the future use of the property, and the proper design will be unique to a specific site and should be based on a careful review process. In case of Manado, urban changed occurred significantly in very short term.
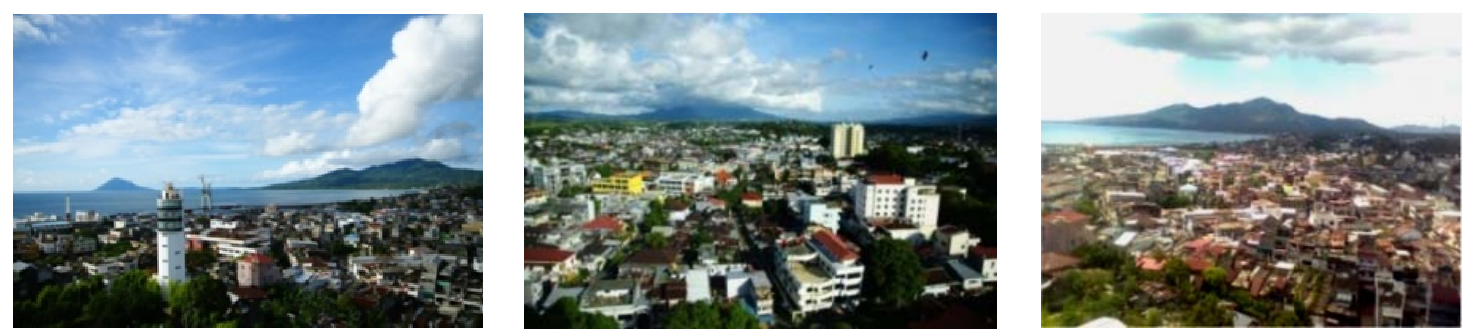

Figure.1. Aerial view of Manado City (source: YP Photography and authors)

\subsection{Related studies}

There are fundamental differences concerning the method of calculation of the thermal comfort for indoor and outdoor, especially in tropical humid environment. At outdoor penetration of direct solar radiation and its radiant temperature can affect significantly 
the level of human thermal comfort. Contrary in the closed room, the radiant temperature (as average of radiant temperatures of internal surfaces: wall-ceiling-floor) is similar or has little difference than indoor air temperature.
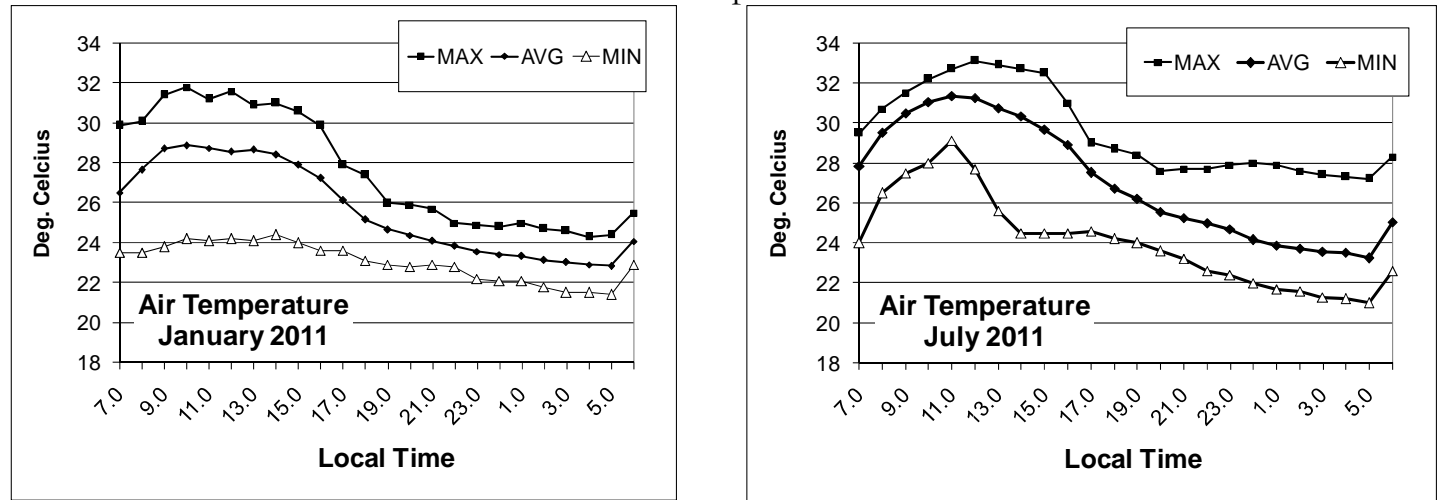

Figure.2. Air temperature profile (source: Meteorology Station of Manado 2011)
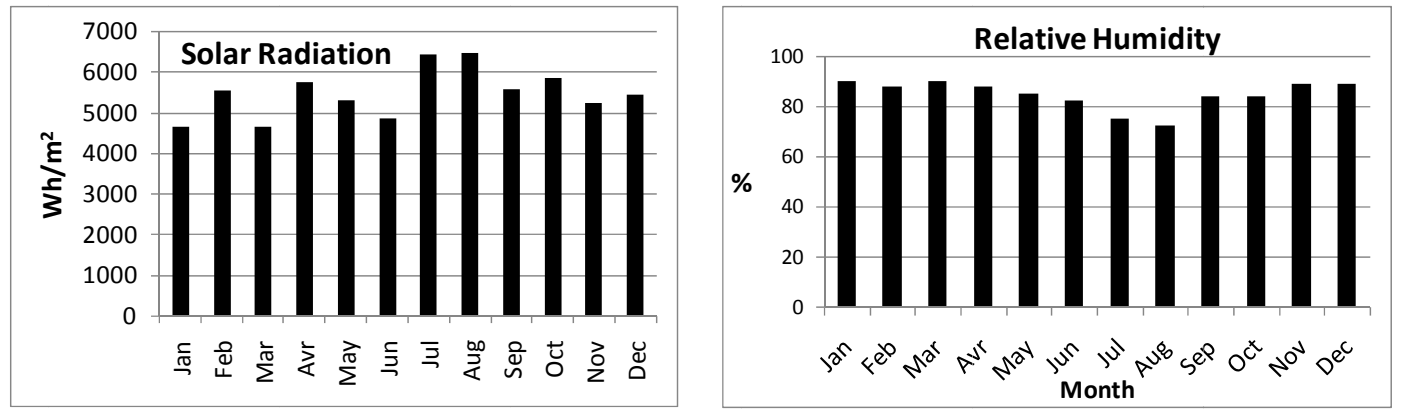

Figure.3. Monthly average solar Radiation and bumidity (source: Meteorology Station of Manado 2011)
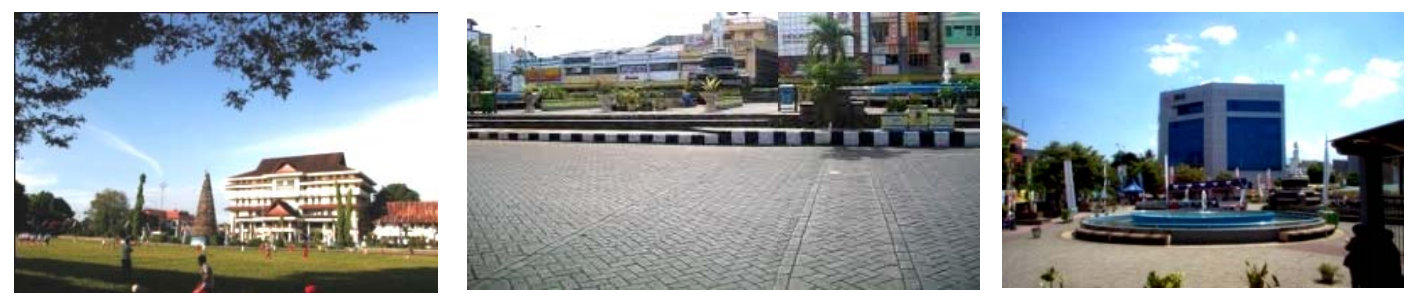

Figure.4. Some open spaces in Manado

That's why in closed space the radiant temperature may not strong enough as determinant variable to influence the perception of thermal comfort. At the outdoor the radiant temperature from solar radiation (direct or indirect) may sting the body skin and cause a feel of uncomfortable thermally. In addition, at outside air velocity is generally greater than in closed room, fortunately the air mass may support the process of achievement of thermal comfort by convection and sweat evaporation. In this context, Arens E and Ballanti D (1997) through a field study, has found significant effect of wind speed on human comfort for walking people in open space. 
The studies of Nikolopoulou \& Steemers (2003), Nikolopoulou, Lykoudis and Kikira (2008) and Ahmed KS (2003) concerning the investigation of human thermal comfort in outdoor space, indicate that when the same climatic condition is applied, the response of discomfort at outdoor space is generally smaller compared to the situation when people are in closed room. There is then, a tendency for people, will be more tolerant in response to climatic conditions at outside than in a closed space.

Researches on modeling the thermal comfort calculations for outdoor space, especially in the case of humid tropical climate are still relatively rare, mostly more interested for the cases of indoor space. If there are the models are based on empirical studies of outdoor space in cold, temperate and sub tropical climate areas, which are generally based on field studies in cities in America, Europe, Japan, Hongkong-China, and Australia. Those such researches carried out by Huang J (Huang et al, 2007), Matzarakis, Mayer \& Rutz (2003), Nikolopoulou M, Lykoudis and Kikira M (2008), Lin TP, Matzarakis and Huang (2010), Scudo G and Dessi V (2006), J R Spagnolo and de Dear (2003) etc. Thermal comfort calculation model that be generated through a number of studies by those researchers may be not necessarily appropriate to be applied in cases of humid tropical climate, because of possible differences in the perception of comfort by people in different geographical habitation.

Some of the authors who conducted researches on outdoor thermal comfort, proposed regression equations as contribution in modeling calculation for practice quantification of outdoor thermal comfort perception. The regression equations are mostly functions of climate variables such are solar radiation, air temperature, air humidity, wind speed, and radiant temperature, as shown in Table 1.

Some others researchers have also proposed the temperature index to measure the level of comfort for people at a particular climatic environment, as the Out_SET (Outdoor Standard Effective Temperature), and TEP (Temperature Effective Psychologically) by Monteiro and Alucci (2009).

\section{Table.1.}

Regression Equations for outdoor thermal comfort

\begin{tabular}{|c|c|c|}
\hline Author(s), Year & Equation & Climate \\
\hline $\begin{array}{l}\text { Monteiro L M and Alucci M } \\
\text { P, } 2009\end{array}$ & $\begin{array}{l}\text { Tsp= }=3.557+0.0632 \mathrm{Ta}+0.0677 \mathrm{Tmr} \\
+0.0105 \mathrm{RH}-0.304 v\end{array}$ & Sub Tropical \\
\hline $\begin{array}{l}\text { Nikolopoulou M, Lykoudis } \\
\text { S, Kikira M, } 2003\end{array}$ & $\begin{array}{l}A S V=0.061 \mathrm{Ta}+0.091 \mathrm{Tg}-0.324 v+0.03 \mathrm{RH}- \\
1.455\end{array}$ & Moderate \\
\hline Cheng V, Ng Edward, 2008 & $\begin{array}{lll}T s_{(\text {CHENG })}=0.1895 \mathrm{Ta} & -0.7754 v & +0.0028 . \mathrm{S} \\
+0.1953 \mathrm{hr}-8.23 & & \\
\end{array}$ & Sub Tropical \\
\hline $\begin{array}{l}\text { Nicol F, Wilson E, } \\
\text { Ueberjahn-Tritta } \\
\text { Nanayakkara L and Kessler } \\
\text { M, 2006 }\end{array}$ & $C=1.761+0.132 \mathrm{Ta}+0.00108 S-0.432 v^{0.5}$ & Cold \\
\hline $\begin{array}{l}\text { Monteiro L M and Alucci M } \\
\mathrm{P}, 2009\end{array}$ & $\begin{array}{l}\text { TEP }=-3.777+0.4828 \mathrm{Ta}+0.5172 \mathrm{Trm}+ \\
0.0802 \mathrm{RH}-2.322 \mathrm{va}\end{array}$ & Sub Tropical \\
\hline $\begin{array}{l}\text { Givoni \& Noguchi (Source: } \\
\text { Gaitani and Santamouris, 2005) }\end{array}$ & $\begin{array}{l}T s_{\text {GIVONII }}=1.7+0.1118 \mathrm{Ta}+0.0019 S-0.322 v- \\
0.0073 \mathrm{RH}+0.0054 \mathrm{Ts}\end{array}$ & Cold \\
\hline
\end{tabular}


A very good study by Mayer and Hoppe also proposed another temperature index that is known as PET (Physiologically Effective Temperature), a physiologically indices that were derived from the human energy balance for the assessment of the thermal complex. The PET which is limited for case of people wearing 0.9 clo with $200 \mathrm{~W}$ (activity) is now integrated into the RayMan Model (Matzarakis A, Rutz F, and Mayer H, 2007).

\section{Methods}

The methods of the study consist of outdoor experiment, measurements and regression analysis. By applying outdoor experimentation, 300 samples of adults participated as respondents/subjects (aged between 17 to 50 years) consisted of 180 men and 120 women. They were asked to wear a type of lightweight tropical clothing (0.5 $0.7 \mathrm{clo}$ ). Their weight and height were also measured in order to obtain inputs for calculating body surface area. The subjects were divided into 2 groups following to two types of location, that is at a place under shaded of trees (protected from direct sunlight), and at other place where it was fully exposed to direct sunlight (open-sky or sunny). These groups were then divided again into 3 sub groups of activities: normal walking $\left(1.8-2.2 \mathrm{~km} / \mathrm{h}\right.$; met $\left.=110 \mathrm{~W} / \mathrm{m}^{2}\right)$, brisk walking $\left(4-5 \mathrm{~km} / \mathrm{h}\right.$; met $\left.=200 \mathrm{~W} / \mathrm{m}^{2}\right)$ and sitting with medium activity (reading, speaking, doing computer). A treadmill was used as equipment for the samples/ subjects for walking facility with a constant speed. At same time a breeze of wind was directed to the body by applying a standing fan with a certain air velocity.

Each subject has walked on treadmill for 2 minutes 5 times, with a pause of about 2 minutes each. After walking of each 2 minutes, at a pause time, they filled simple questionnaire concerning their thermal comfort perception. At the same time, measurement of surface body skin temperature, air temperature, humidity, land surface temperature, air velocity and globe temperature were done. Measurement equipments used were: thermo-hygrometer, anemometer, infrared thermometer, solar-power meter, and globe thermometer. Period and time of outdoor experimentation was from May to July 2011 and July to September 2012 at day time (08.00 am to $05.00 \mathrm{pm})$.

The data obtained from measurement and questionnaires were then compiled and analyzed with focusing on the correlation among three factors: the value represent of thermal comfort perception, climate characteristics, and parameters of the human body. Then proceed with statistical analysis to obtain the regression equation $Y=f(x, y)$, where ' $Y$ ' is a number that indicates sense of thermal comfort, and ' $X$ ' is the climate variables (air temperature, globe temperature, relative humidity, air velocity, and solar radiation), ' $y$ ' is the parameters and variable of the body (height, weight, skin temperature and dress). Table 2 shows the syntax of the thermal response that corresponded to integer value of ' $Y$ '. More detail explanation method of the study has published by same authors (Sangkertadi and Syafriny, 2012)

\section{Result and discussion}

\subsection{The regression equations}

Based on the data from measurements and questionnaires and through a statistical analysis, three regressions equations have been successfully developed, and that 
represent three modes of activities: normal walking, brisk walking and seated with a moderate action.

Table. 2. Description of ' $Y$ '

\begin{tabular}{|c|c|}
\hline $\begin{array}{l}\text { Value of } \\
\text { ' } Y \text { ' }\end{array}$ & $\begin{array}{l}\text { Comfort Level Perception } \\
\text { (refereed to PMV scale) }\end{array}$ \\
\hline-2 & Cold \\
\hline-1 & Cool \\
\hline 0 & Comfort/ Neutral \\
\hline 1 & Warm / Slightly hot \\
\hline 2 & Hot \\
\hline 3 & Very Hot \\
\hline 4 & Very-very Hot and feel pain \\
\hline 5 & Very not tolerable \\
\hline
\end{tabular}

For the case of normal walking (speed of about $2 \mathrm{~km} / \mathrm{h}$ ), the regression equation is as follows:

$Y_{I S}=-3.4-0.36 v+0.04 \mathrm{Ta}+0.08 \mathrm{Tg}-0.01 \mathrm{RH}+0.96 \mathrm{Adu}$

(Multiple $\mathrm{R}=0.70$ )

For the case of brisk walking (speed of about $4-5 \mathrm{~km} / \mathrm{h}$ ) the regression equation was obtained:

$Y_{I C}=2.53-0.29 v+0.11 \mathrm{Ta}+0.05 \mathrm{Tg}-0.0009 \mathrm{RH}+0.35 \mathrm{Adu}$

(Multiple $\mathrm{R}=0.5$ )

The regression equation for the case of seated people with moderate activity, is as follow:

$Y_{D S}=-7.91-0.52 v+0.05 \mathrm{Ta}+0.17 \mathrm{Tg}-0.0007 \mathrm{RH}+1.43 \mathrm{Adu}$

(Multiple $\mathrm{R}=0.75$ )

Where :

v : : Air velocity $(\mathrm{m} / \mathrm{s})$

Ta : Air temperature $\left({ }^{\circ} \mathrm{C}\right)$

$\mathrm{Tg} \quad$ : Globe Temperature $\left({ }^{\circ} \mathrm{C}\right)$

RH : Relative Humidity (\%)

Adu : Area of body skin (surface of $d u$ Bois, $\mathrm{m}^{2}$ )

The coefficients and variables of the new three equations above are different from equations by other authors that be shown in the Table.1. In addition, the new equations take into account of the body skin surface $(A d u)$ as variable, which is not considered by the other comparator equations.

Some calculations by using the new equations have been done in order to know the sensitivity of the equations to micro-climate variables, where the results are shown by the graphics in the Figure.4a to $4 \mathrm{~h}$. The objective is to know the effect of air velocity on outdoor thermal comfort, coupled with variation of temperatures. The different values of $\mathrm{Ta}$ (air temperature) and $\mathrm{Tg}$ (globe temperature) were applied. It is shown, that wind velocity may influence to increase the sense of comfort significantly. It is indicated that increase of air velocity of $1 \mathrm{~m} / \mathrm{s}$ may improve the scale of comfort level of around 0.5 to 1.5 on average for three types of activity. It is also shown that $T g$ as representation of mean radiant temperature play significant role in perception of comfort (presented in the Figures $4 \mathrm{~h}$ and $4 \mathrm{f}$ ). 

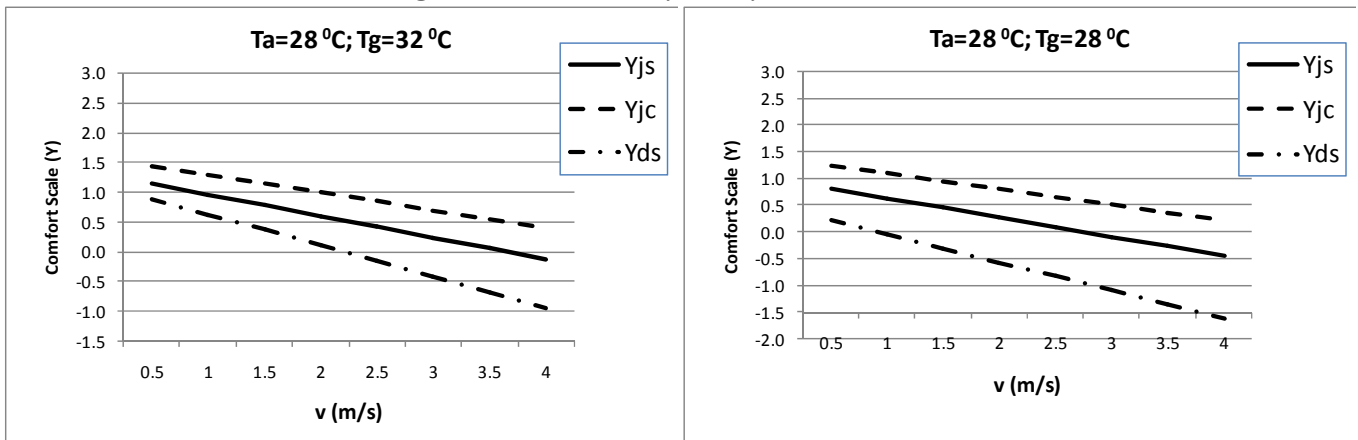

Figure.4a

\section{Figure.4b}
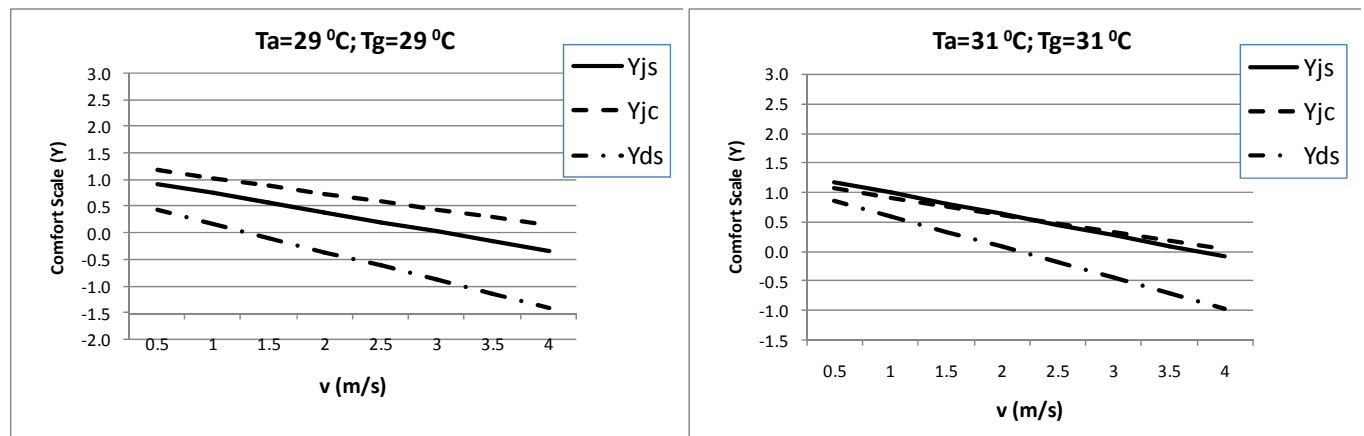

Figure.4c

Figure.4d
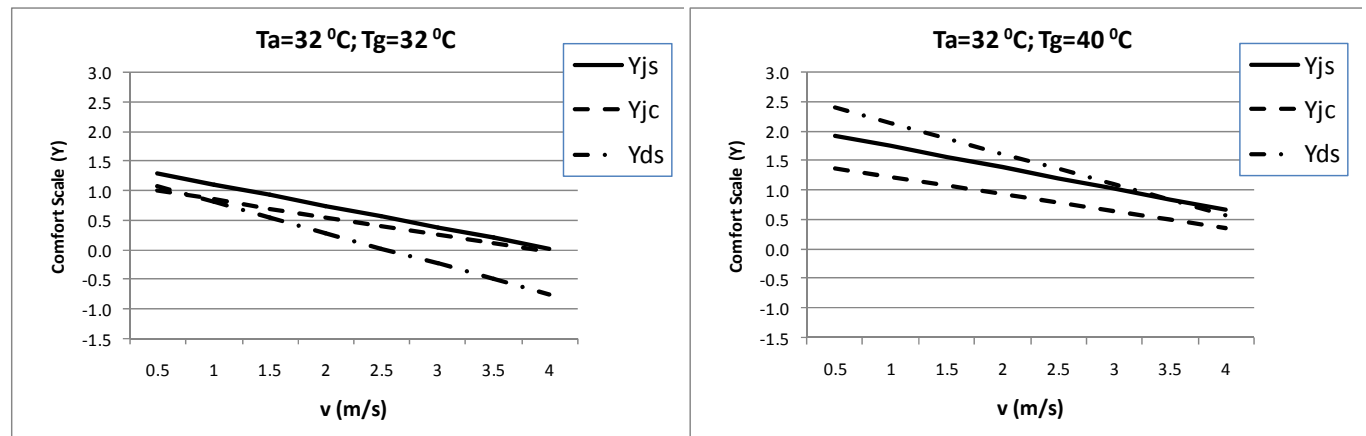

Figure.4e

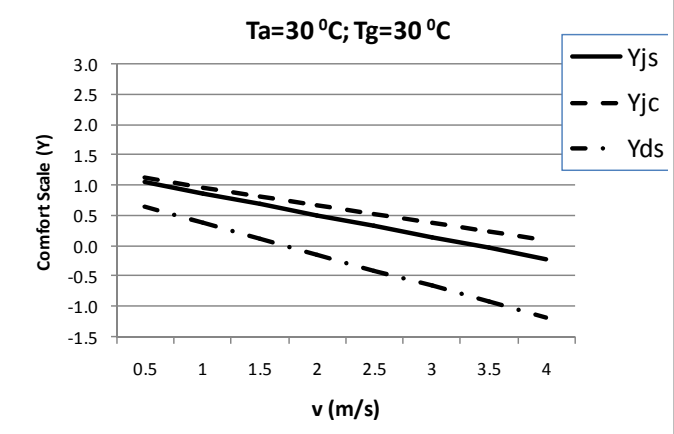

Figure. $4 f$

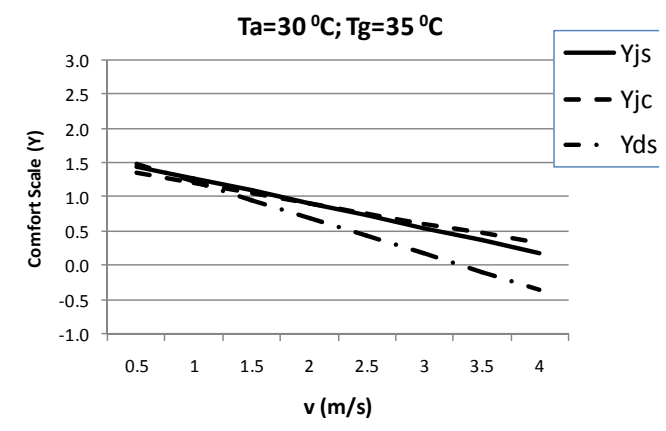

Figure. $4 g$

Figure.4h

(C) 2014 The Authors. Journal Compilation C 2014 European Center of Sustainable Development. 
The new regression equations that were found through this study are useful as tool aid for designing facilities in open-spaces of the cities in warm humid environment. For example, when designing of outdoor-cafes, installation of standing fan and canopies, may be required, in order to obtain the temperatures and air velocity sufficiently for user comforts (Figure.5). In this case, the optimum wind speed and maximum of radiant temperature can be determined by using the equation. Then it can be decided the position and types of fan, types of canopy and surface material at open-space. However to apply the equations, it requires climatic data that can be obtained from the results of measurements, such as from meteorological stations or by direct measurement in situ. In general, many of published-meteorological-data, mentions only the hourly-daily of air temperature, humidity and wind. In order to complete the lack of data on solar radiation, radiant temperature and globe temperature, it can be obtained through calculations. The computer program 'Matahari' developed by Sangkertadi (2009), can be used to calculate solar radiation on various surfaces position. While to calculate $T g$, it can be used equation from the study of Dimiceli, Piltz and Amburn (2011) that based on the values of Ta, $v$ and $\mathrm{RH}$.
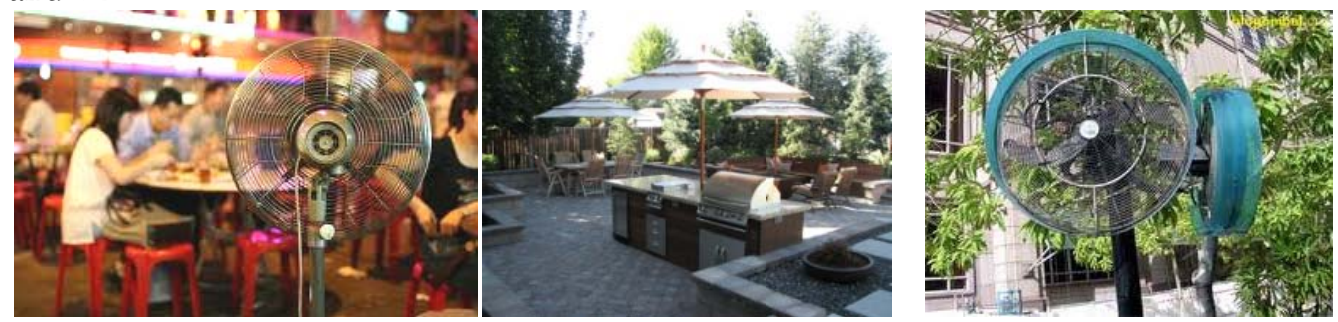

Figure.5. Fan and Canopy at open-spaces in tropical humid area.

\subsection{Comparative Study}

Comparison the equations with other calculation models (Table.1) was also realized. The objective is as validation of the equations by a comparative manner. It was found that there are difference values between the results by using the new equations from the study and other models where applying the same values of variables. The climate variables that applied for comparison are shown in the Table. 3 which is typically represented of humid-tropical climate.

The comparison of equations which is shown in the Figure. 6 indicates that the results of regression equation $Y j s$ are almost the same as the results of Tsp. It is logical, as Tsp is formulation based on sub tropical climate, in which climatologically, it does not have widely differences compared to tropical humid climatic situation. Figure.6 also shows that there are significantly different results of calculation, between using new equation $Y j s$ and other models such are $C, T s$, and $A S V$, when a constant air velocity of $1 \mathrm{~m} / \mathrm{s}$ is applied.

\section{Conclusion}

Components of thermal comfort equation for outdoor spaces formed not only of microclimate factors but also the human factors (activity, size and clothing). 


\begin{tabular}{|c|c|c|c|c|c|c|}
\hline \multirow{2}{*}{ Hour } & $\mathrm{S}$ & $\mathrm{RH}$ & $\mathrm{Ta}$ & $\mathrm{Ts}$ & $\mathrm{Tg}$ & $\mathrm{Trm}$ \\
\cline { 2 - 7 } & $\left(\mathrm{W} / \mathrm{m}^{2}\right)$ & $(\%)$ & $\left.{ }^{0} \mathrm{C}\right)$ & $\left.{ }^{0} \mathrm{C}\right)$ & $\left({ }^{0} \mathrm{C}\right)$ & $\left({ }^{0} \mathrm{C}\right)$ \\
\hline 7 & 113.42 & 57 & 27.5 & 31.0 & 37.0 & 39.2 \\
\hline 8 & 305.21 & 56 & 28.0 & 37.4 & 44.9 & 48.9 \\
\hline 9 & 488.59 & 55 & 30.2 & 45.2 & 52.9 & 58.3 \\
\hline 10 & 634.90 & 51 & 31.0 & 50.5 & 58.0 & 64.4 \\
\hline 11 & 728.43 & 52 & 31.5 & 53.8 & 61.1 & 68.2 \\
\hline 12 & 760.50 & 51 & 31.2 & 54.5 & 61.7 & 69.0 \\
\hline 13 & 728.43 & 52 & 31.9 & 54.2 & 61.5 & 68.6 \\
\hline 14 & 634.90 & 52 & 31.0 & 50.5 & 58.0 & 64.4 \\
\hline 15 & 360.96 & 56 & 28.4 & 39.5 & 45.2 & 49.2 \\
\hline 16 & 305.21 & 59 & 27.1 & 36.5 & 44.0 & 48.0 \\
\hline 17 & 113.42 & 59 & 27.3 & 30.8 & 36.8 & 39.0 \\
\hline
\end{tabular}

Table.3.

Climatic variable (July in Manado) as input of calculation for comparison

Comparison of the regressions v=1 m/s; July; Tropics Humid

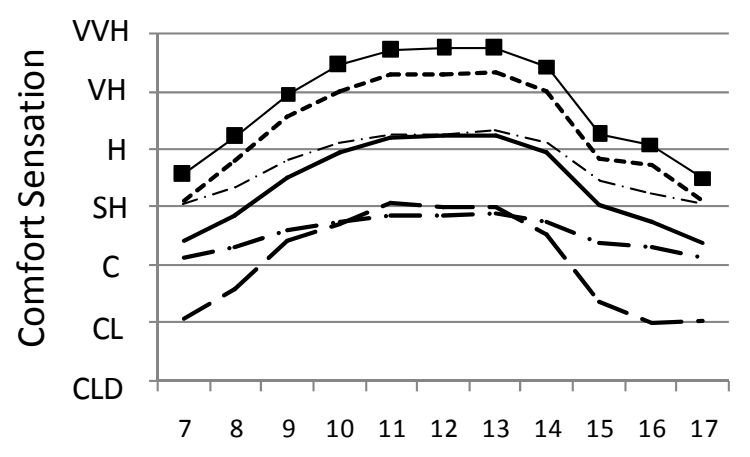

Figure.6. Comparison of equations; $C=$ Comfort; SH=Slightly Hot; $\mathrm{H}=\mathrm{Hot} ; \mathrm{VH}=\mathrm{Very}$ Hot; $\quad V V H=V$ ery Very Hot; $C L=$ Cool; $C L D=$ Cold

\section{Hour}

The sense of thermal comfort at outdoor spaces, is a function integrated of variables and parameters of air temperature $(T a)$, radiant temperature $(T g)$, wind speed $(v)$ and human properties (activity, type of clothing, body size). Through this study it is found that thermal comfort equation for outdoor space in warm and humid environments is specific, and different from other equations which are available for other climates.

The study shows, that in humid tropical climate, wind mass that touch the human body, can affect the sense of outdoor comfort significantly. Beside, mean radiant temperature that represented by global temperature influence the comfort significantly.

Therefore, the practice to operate the standing fan in the outdoor space is reasonable to get a sense of comfort for the user. In addition, efforts to reduce radiant temperature by applying shading devices, and application of soft surface material and non-heat reflector, are also the way to reach friendly environment of the cities in warm humid climate. 


\section{References}

Ahmed K S, (2003), Comfort in Urban Spaces: defining the boundaries of outdoor thermal comfort for the tropical urban environment, Journal: Energy \& Building, vol 35 - 2003

Arens E and Ballanti D, (1997), Outdoor Comfort of Pedestrians in Cities, Proceedings of The Conference on Physical Environment, Upper Derby, PA, US 1997.

Cheng V, and Ng E, (2008), Wind for Comfort in High Density Cities, Proceedings of The Conference on Passive and Low Energy Architecture, Dublin 22 - 24 October 2008.

Dimiceli V E, Piltz S F, Amburn S A, (2011), Estimation of Black Globe Temperature for Calculation of the Wet Bulb Globe Temperature Index. Proceedings of the World Congress on Engineering and Computer Science-2011 Vol II WCECS 2011, October 19-21, 2011, San Francisco, USA

Fanger P O, (1970), Thermal Comfort - Analysis and Applications in Environmental Engineering, McGraw Hill, New York.

Gaitani, N, Santamouris M, Mihalakakou G, (2005), Thermal comfort conditions in outdoor spaces, Proceedings of International Conference "Passive and Low Energy Cooling May 2005, Santorini, Greece.

Givoni B, and Noguchi, M, (2000), Issues in outdoor comfort research. Proceedings of The Conference Passive and Low Energy Architecture, London, 2000.

Huang J, (2007), Prediction of air temperature for thermal comfort of people in outdoor environments. Int. Journal on Biometeorology Vol.51, 2007

International Standard Organization, (2003), ISO Standard 7730: Moderate thermal environments - Determination of the PMV and PPD indices and specification of the conditions for thermal comfort, 2003.

Lin, T.-P. , Matzarakis, A., Hwang, R.-L., Huang, Y.-C, (2010), Effect of pavements albedo on long-term outdoor thermal comfort. Proceedings of the 7th Conference on Biometeorology, 2010.

Lin, T.-P., Andrade, H., Hwang, R.-L., Oliveira, S., Matzarakis, A.,(2008), The comparison of thermal sensation and acceptable range for outdoor occupants between Mediterranean and subtropical climates. Proceedings 18th International Congress on Biometeorology, September 2008.

Matzarakis A, Mayer H, Rutz F, (2003), Radiation and Thermal Comfort, Proceeding of $6^{\text {th }}$ Hellenic Conference in Meteorology, Climatology and Atmospheric Physics, 2003.

Matzarakis A, Rutz F, and Mayer H, (2007), Modelling radiation fluxes in simple and complex environmentsapplication of the RayMan model. Int J Biometeorology, Vol. 51, 2007.

Monteiro L M, Alucci M P, (2009), An Outdoor Thermal Comfort Index for the Subtropics. Proceeding 26 th PLEA, 2009

Nicol F, Wilson E, Ueberjahn-Tritta A, Nanayakkara L and Kessler M, (2006), Comfort in outdoor spaces in Manchester and Lewes, UK, Proceedings of conference: Comfort and Energy Use in Buildings - Getting them Right, Cumberland Lodge, Windsor, UK, 27-30th April 2006. London

Nikolopoulou, M and Steemers, K, (2003), Thermal comfort and psychological adaptation as a guide for designing urban spaces, Energy and Buildings, vol 35. 2003

Nikolopoulou, M, Lykoudis, S and Kikira, M, (2008), Thermal comfort in urban spaces: field studies in Greece, Proceedings of the fifth International Conference on Urban Climate. September, 2008 Lodz, Poland.

Nasir R A, Ahmad S Sh and Ahmed A Z, (2012), Psychological Adaptation of Outdoor Thermal Comfort in Shaded Green Spaces in Malaysia, Procedia - Social and Behavioral Sciences 68, 2012

Sangkertadi and Syafriny R, (2012), Proposition of Regression Equations to Determine Outdoor Thermal Comfort in Tropical and Humid Environment, IPTEK, The Journal for Technology and Science, Vol. 23, Number 2, May 2012.

Sangkertadi, (1994). Contribution al'Etude du ComportementThermoaureulique des Batiments en Climat Tropical Humide. Prise en Compte de la Ventilation Naturelle dans l'Evaluation du Confort, These de Doctorat (unpublished), INSA de Lyon.

Sangkertadi. Petunjuk Pemakaian Program 'Matahari',(2009), Fakultas Teknik Unsrat, Manado (unpublished).

Scudo G and Dessi V, (2006). Thermal comfort in urban space renewal, Proceeding 23th PLEA, 2006

Spagnolo J and De Dear R, (2003), A field study of thermal comfort in outdoor and semi-outdoor environments in subtropical Sydney, Australia, Building and Environment, Volume 38, Issue 5, May, 2003. 